\title{
Disease activity and joint damage progression in early rheumatoid arthritis: relation to $\operatorname{IgG}, \operatorname{IgA}$, and IgM rheumatoid factor
}

\author{
K B Eberhardt, L Truedsson, H Pettersson, B Svensson, L Stigsson, J L Eberhardt, \\ F A Wollheim
}

\begin{abstract}
The clinical and biochemical correlations with joint damage progression over two years in a consecutive group of 68 patients with rheumatoid arthritis with disease duration of less than two years are reported. Joint damage was assessed with Larsen's severity scale and a measure of change in progression rate constructed. Initial haemoglobin concentration, Ritchie index, and Waaler-Rose titre in combination accounted for one third of the variance in joint damage progression. Rheumatoid factor (RF) concentrations were followed with enzyme linked immunosorbent assays (ELISAs) for IgG RF, IgA RF, and IgM RF. The RF concentrations, except IgG RF, decreased with time; significant correlations between RFs and disease activity were few and barely clinically useful. After two years IgG RF correlated significantly with a radiological score if early non-erosive changes were omitted. All RFs tended to correlate better with this radiological score at all three observation points. Analyses of the change in progression rate indicated a time delay between development of radiographic changes and increase of IgG RF. These results suggest an indirect relation between RFs and joint damage. Clinical and biochemical improvements in early RA occur despite joint damage progression, and conventional markers have insufficient predictive value.
\end{abstract}

Lund, Sweden

K B Eberhardt

F A Wollheim

Department of Medical Microbiology, University Hospital, Lund, Sweden

L Truedsson

Department of

Diagnostic Radiology,

University Hospital,

Lund, Sweden

H Pettersson

Rheumatology Unit,

Helsingborg General

Hospital, Sweden

B Svensson

Department of

Diagnostic Radiology,

Helsingborg General

Hospital, Sweden

L Stigsson

Institute of Occupational and Environmental Medicine, University

Hospital, Lund, Sweden J E Eberhardt

Correspondence to:

Dr K B Eberhardt,

Department of Rheumatology,
University Hospital, S-221 85

Lund, Sweden.

Accepted for publication

22 January 1990
Enzyme linked immunosorbent assays (ELISAs) permit the detection and measurement of rheumatoid factors (RFs) of various immunoglobulin classes. The clinical value of $\mathrm{RF}$ isotype measurements is currently discussed. We have previously reported that RFs assayed at the start of a prospective study of early rheumatoid arthritis were not associated with erosive disease during the first two years. Measures of disease activity recorded at the same time did not correlate with the RF concentrations. ${ }^{1}$ This study has now been expanded to evaluate a possible association between severity of radiological changes and RFs and to determine whether fluctuations in $\mathrm{RF}$ concentrations might reflect fluctuations in disease activity assessed serially over two years.

\section{Patients and methods}

Seventy one patients from primary care units in disease duration of less than two years were the area with definite rheumatoid arthritis ${ }^{2}$ and enrolled in the study. During a follow up of 24 months two patients died owing to pulmonary carcinoma, and another patient was reclassified as psoriatic arthritis. The remaining 68 patients (26 men, 42 women) had a mean (SD) age of $56 \cdot 1(14 \cdot 1)$ years and mean (SD) disease duration at the start of the study of $11 \cdot 8(6 \cdot 8)$ months.

During the study period about half of the patients were treated with slow acting antirheumatic drugs, mostly antimalarial drugs (20 patients) or D-penicillamine (10 patients).

\section{CLINICAL EVALUATION}

The patients were evaluated at regular intervals by clinical and laboratory measures as previously described. ${ }^{1}$ Briefly, the articular disease was estimated by the Ritchie index ${ }^{3}$ and an active joint count. ${ }^{4}$ Grip strength was measured with a sphygmomanometer (mean of readings for right and left hand). Functional capacity was assessed with a validated Swedish version of the Stanford Health Assessment Questionnaire disability index. ${ }^{5}$ Pain during the preceding week was recorded on a visual analogue scale.

\section{RADIOLOGICAL EVALUATION}

Radiographic examinations of hands, wrists, and feet were performed at study start and after 12 and 24 months. All radiographs were evaluated by one experienced radiologist and the findings were scored using the method described by Larsen. ${ }^{7}$ Thus each joint was compared with standard reference films and assigned a score between 0 (normal) and 5 (mutilating changes). Severity stage 1 corresponded to non-erosive changes-that is, soft tissue swelling and periarticular osteoporosis, and stages 2-4 corresponded to increasing degrees of erosions and joint space narrowing. Thirty two joints were evaluated: the wrists, the metacarpophalangeal joints $\mathrm{I}-\mathrm{V}$, interphalangeal joint $\mathrm{I}$, proximal interphalangeal joints II-V of the hands and the interphalangeal joint I and metatarsophalangeal joints II-V of the feet. The wrist score was multiplied by five and all the scores added up, together forming the joint damage index. In addition, a modified index omitting severity stage 1 was calculated.

In analyses of radiological outcome the absolute difference between scores after two years and at study start was taken into account. A new radiological measure assessing the change in progression rate between the first and second 12 month period was constructed according to the formula illustrated in the figure. The usefulness of the new index was also analysed. 
Change in progression rate between the two observation intervals. $s=$ radiological score; $t=$ time.

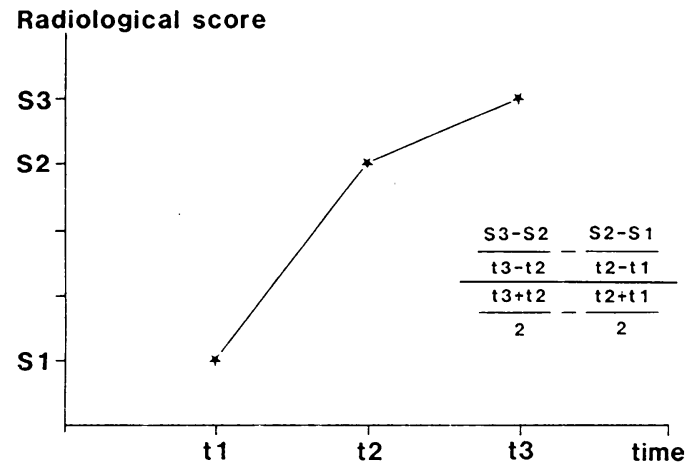

RHEUMATOID FACTOR MEASUREMENTS

Rheumatoid factors of $\operatorname{IgG}, \operatorname{Ig} A$, and $\operatorname{IgM}$ classes were analysed. ${ }^{8}$ Briefly, human serum albumin was adsorbed onto the plastic surface of microtitre wells and rabbit IgG antibodies specific for the human serum albumin were added. After addition of the test sample bound RFs were detected by enzyme labelled immunoglobulin class specific $F\left(a b^{\prime}\right)_{2}$ fragments.

The results of the ELISAs were expressed as arbitrary units (AU) compared with a local standard said to contain $1000 \mathrm{AU} / \mathrm{ml}$. Concentrations of $4 \mathrm{AU} / \mathrm{ml}$ or more of $\operatorname{IgA~RF}$ and $\operatorname{IgM}$ $\mathrm{RF}$ and $6 \mathrm{AU} / \mathrm{ml}$ or more of IgG RF were considered positive. ${ }^{1}$

An IgG fraction was used for sensitisation of sheep red cells and a Waaler-Rose test performed according to standard procedures. ${ }^{9} \mathrm{~A}$ titre of $1 / 64$ corresponding to $50 \mathrm{IU} / \mathrm{ml}^{10}$ was considered positive.

\section{STATISTICAL ANALYSES}

Differences between clinical and laboratory measures obtained at 0,12 , and 24 months were evaluated with Wilcoxon's test for paired data. Correlations were estimated with Spearman's rank correlation coefficient method. Owing to the large number of correlations calculated the level of significance was set at 0.002 . Correlations between RFs and different measures of disease activity were calculated both for the absolute values at 0,12 , and 24 months and for changes between the observation times.

Backward stepwise multiple regression was performed using a radiological outcome measure as dependent variable and the clinical and laboratory measures as independent variables. Variables contributing with $F<4.0$ were excluded from the regression. The validity of the regressions was assessed by residual analyses.

\section{Results}

Table 1 shows the results of clinical, laboratory, and radiological assessments at 0,12 , and 24 months. Most clinical and laboratory measures improved with time. In contrast, the radiological status deteriorated.

More than half of the sera contained all antiglobulin isotypes simultaneously and about $15 \%$ of the sera contained a mixture of IgA RF and IgM RF. No serum containing only IgA RF was found. Table 2 shows the concentrations of the RFs. The rheumatoid factor concentrations, with the exception of IgG RF, were significantly lower at the end. RF concentrations correlated significantly with each other throughout the study, though all correlations decreased with time. No significant correlations were found between the absolute values of the RF concentrations and various measures of disease activity at the three observation points. In the analysis of changes between 0 and 12 months IgM RF and Waaler-Rose tests correlated significantly with $C$ reactive protein $\left(r_{s}=0.44\right.$ for both correlations). Table 3 shows the correlations between different RF isotypes and the absolute values of the ordinary and modified joint damage scores, respectively, over time. IgG RF correlated significantly with the modified score after two years. All the RF isotypes tended to correlate better with the modified score at all three observation points. $C$ reactive protein

Table 2 Concentrations of rheumatoid factors ( $R F s$ ) expressed in arbitrary units/ml at study start and after 24 months. Results given as medians (1st; 3rd quartile)

\begin{tabular}{llll}
\hline & Month 0 & Month 24 & $\begin{array}{l}{ }^{*} p \text { Value } \\
\text { O v 24 months }\end{array}$ \\
\hline IgA RF & $37 \cdot 5(6 \cdot 5 ; 74 \cdot 5)$ & $21(6 ; 42)$ & $\leqslant 0 \cdot 001$ \\
IgM RF & $92(30 ; 147 \cdot 5)$ & $49(22 ; 105)$ & $\leqslant 0 \cdot 001$ \\
IgG RF & $12 \cdot 5(0 ; 32)$ & $14(5 ; 37)$ & NS
\end{tabular}

*Wilcoxon's test for paired data (two tailed).

Table 3 Correlations $\left(r_{s}\right)$ t over time between the different rheumatoid factor $(R F)$ isotypes and the absolute values of the two radiological scores

\begin{tabular}{|c|c|c|c|c|c|c|}
\hline & \multicolumn{2}{|c|}{ Observation 1} & \multicolumn{2}{|c|}{ Observation 2} & \multicolumn{2}{|c|}{ Observation 3} \\
\hline & $f D t$ & $M F D t$ & $\mathcal{F D}$ & $M F D$ & $\mathcal{F} D$ & $M F D$ \\
\hline $\begin{array}{l}\text { IgA RF } \\
\text { IgM RF } \\
\text { IgG RF }\end{array}$ & $\begin{array}{l}0.05 \\
0.07 \\
0.17\end{array}$ & $\begin{array}{l}0 \cdot 12 \\
0 \cdot 14 \\
0 \cdot 19\end{array}$ & $\begin{array}{l}0.08 \\
0.20 \\
0.27\end{array}$ & $\begin{array}{l}0.23 \\
0.31 \\
0.32\end{array}$ & $\begin{array}{l}0.10 \\
0.19 \\
0.34\end{array}$ & $\begin{array}{l}0 \cdot 22 \\
0 \cdot 27 \\
0 \cdot 42^{*}\end{array}$ \\
\hline
\end{tabular}

$*=\mathrm{p} \leqslant 0.002$.

$\dagger r_{s}=$ Spearman's rank correlation coefficient; JD=joint damage score; MJD=modified joint damage score omitting non-erosive changes.

Table 1 Some clinical and laboratory measures at 0, 12, and 24 months. Results given as medians (1st; 3rd quartile)

\begin{tabular}{|c|c|c|c|c|c|c|}
\hline Measure & Month 0 & $\begin{array}{l}{ }^{*} p \text { Value } \\
0^{\mathrm{v}} 12 \text { months }\end{array}$ & Month 12 & $\begin{array}{l}{ }_{1}^{*} p \text { Value } \\
12 \mathrm{v} 24 \text { months }\end{array}$ & Month 24 & $\begin{array}{l}{ }^{*} p \text { Value } \\
0-24 \text { months }\end{array}$ \\
\hline $\begin{array}{l}\text { Active joint count } \\
\text { Grip strength (mmHg) } \\
\text { Morning stiffness }(\mathrm{min}) \\
\text { Pain }(0-3) \\
\text { HAQ† disability-index }(0-3) \\
\text { Haemoglobin }(\mathbf{g} / \mathbf{l}) \\
\text { ESR† }(\mathbf{m m} / \mathbf{h}) \\
\text { CRP† }(\mathbf{m g} / \mathbf{l}) \\
\text { Joint damage index }\end{array}$ & $\begin{array}{l}8(3 ; 13) \\
91 \cdot 5(60 ; 150) \\
60(20 ; 120) \\
1 \cdot 4(0 \cdot 9 ; 2 \cdot 1) \\
0 \cdot 9(0 \cdot 5 ; 1 \cdot 5) \\
126 \cdot 5(116 \cdot 5 ; 136) \\
24(14 ; 40) \\
<10(<10 ; 45) \\
9(3 ; 22)\end{array}$ & $\begin{array}{l}\leqslant 0.01 \\
\leqslant 0.05 \\
\text { NS } \\
\text { NS } \\
\text { NS } \\
\text { NS } \\
\text { NS } \\
\text { NS } \\
\leqslant 0.001\end{array}$ & $\begin{array}{l}5(1 ; 11) \\
110(68 ; 235) \\
60(0 ; 120) \\
1 \cdot 1(0 \cdot 5 ; 1 \cdot 7) \\
0 \cdot 8(0 \cdot 4 ; 1 \cdot 3) \\
129(120 ; 140) \\
23(12 ; 35) \\
12(<10 ; 30 \cdot 5) \\
22 \cdot 5(9 ; 35 \cdot 5)\end{array}$ & $\begin{array}{l}\leqslant 0 \cdot 001 \\
\text { NS } \\
\text { NS } \\
\leq 0 \cdot 01 \\
\text { NS } \\
\text { NS } \\
\text { NS } \\
\text { NS } \\
\leqslant 0.001\end{array}$ & $\begin{array}{l}3(1 ; 6) \\
130(85 ; 240) \\
52 \cdot 5(0 ; 60) \\
0 \cdot 8(0 \cdot 3 ; 1 \cdot 5) \\
0 \cdot 8(0 \cdot 4 ; 1 \cdot 3) \\
133(119 ; 141) \\
20(11 ; 38 \cdot 5) \\
<10(<10 ; 22) \\
30 \cdot 5(19 \cdot 5 ; 46 \cdot 5)\end{array}$ & $\begin{array}{l}\leqslant 0.001 \\
\leqslant 0.001 \\
N S \\
\leqslant 0.001 \\
N S \\
\leqslant 0.05 \\
N S \\
\text { NS } \\
\leqslant 0.001\end{array}$ \\
\hline
\end{tabular}

*Wilcoxon's test for paired data (two tailed).

†HAQ=Stanford Health Assessment Questionnaire disability index ${ }^{5}$; $E S R=$ erythrocyte sedimentation rate; $C R P=C$ reactive protein 
Table 4 Regression model fitting results for the progression of joint damage over two years

\begin{tabular}{lclc}
\hline $\begin{array}{l}\text { Independent variable } \\
\text { (recorded at study start) }\end{array}$ & $\begin{array}{l}\text { Regression } \\
\text { coefficient }\end{array}$ & Std error & Significance level \\
\hline Constant & 6.37 & $4 \cdot 15$ & \\
Ritchie index & 0.88 & 0.25 & $<0.001$ \\
Haemoglobin* & -0.27 & 0.11 & 0.02 \\
Waaler-Rose† & 1.20 & 0.59 & 0.05 \\
\hline
\end{tabular}

$\mathbf{R}^{2}=\mathbf{0} \cdot 32$.

*The haemoglobin values were normalised to zero mean.

tThe test results were transformed to the number of titre steps.

Table 5 Regression model fitting results for the change in progression rate index

\begin{tabular}{lccc}
\hline $\begin{array}{l}\text { Independent variable } \\
\text { (recorded at I year) }\end{array}$ & $\begin{array}{l}\text { Regression } \\
\text { coefficient }\end{array}$ & Std error & Significance level \\
\hline Constant & 5.12 & 3.34 & \\
Morning stiffness & -0.07 & 0.03 & 0.02 \\
Active joint count & 0.70 & 0.30 & 0.03 \\
IgG RF & -0.42 & 0.11 & $<0.001$ \\
\hline
\end{tabular}

$R^{2}=0 \cdot 21$.

correlated significantly with the ordinary score at 12 and 24 months $\left(r_{s}=0.41\right.$ and 0.44 respectively). Clinical variables such as morning stiffness, grip strength, and active joint count did not correlate significantly with either score. As might be expected the correlations between the two joint damage indices themselves increased with time $\left(r_{s}=0.81,0.85,0.90\right)$.

Regression analyses were performed for the different observation points separately. A combination of the initial values of the Ritchie index, haemoglobin concentration, and RF explained $32 \%$ of the variance in the absolute change of the joint damage index between the start of the study and two years. Age was a confounding factor and was corrected for. Table 4 shows the result of the analysis. The highest correlation obtained for a single variable (haemoglobin) was 0.30 and the combination of variables increased this to $0 \cdot 57$. Twenty five per cent of the variance in the change of the radiological progression rate could be explained by a set of variables-morning stiffness, active joint count, and IgG RF-obtained after 12 months (table 5). It is noteworthy that the correlation with IgG RF was negative. The regression analysis increased the correlation from $0 \cdot 30$ (IgG RF) to $0 \cdot 46$.

\section{Discussion}

The early symptomatic phase of rheumatoid arthritis has attracted increasing attention in several recent studies in the hopes of defining better prognostic variables ${ }^{11-13}$ or gaining therapeutic advantages. ${ }^{14}$ Our study aimed at applying sensitive immunochemical assays for RFs and correlating the results with clinical and radiological features.

Some of the patients in this study had been treated with different slow acting antirheumatic drugs, which might have influenced the RF concentrations. The study design did not allow measurement of possible effects.

One third of the variance in the progression of joint damage over two years could be explained by some of the clinical and laboratory variables obtained at the start of the study. The contributing variables were Ritchie index, haemoglobin concentration, and Waaler-Rose titre. Thus the conventional agglutination test was a more useful indicator of progression rate, though the regression coefficient for the Waaler-Rose test was barely significant.

In analyses of associations between serial changes in RFs and measures of disease activity only a few significant correlations during the first year were obtained, which were of little clinical relevance. This is in accordance with Scott $e t a l$, who found no advantage from serial measurements of IgM RFs and IgG RFs in assessing disease activity in patients during 12 months' treatment with gold or penicillamine. ${ }^{15}$ March et al investigated the ability of different measures obtained initially to predict articular index after one year in patients with early rheumatoid arthritis. ${ }^{16}$ None of IgA RF, IgG RF, or IgM RF contributed to the prediction.

On the other hand, several authors have found RF isotype measurements useful in the assessment of disease activity in patients studied prospectively, ${ }^{17-22}$ though the isotype shown to correlate with disease activity varied between the studies. Some of the variation in the results of the different studies may be due to differences in patient selection. Also some of the studies based their conclusions on a small number of patients. The statistical evaluation of changes over time with many different variables is complicated and various methods have been used, which makes interpretation and comparison difficult. The problem of mass significance also has to be considered and the levels of significance should be set high, which has not always been the case.

In general, the amounts of RFs decreased during the study. An exception were the persisting or even slightly increasing concentrations of IgG RFs reminiscent of the normal class switching sequence during the immunisation process. IgG RFs thus seem to parallel the chronicity of the disease more closely. Similarly, correlation between radiological changes and IgG RF became closer with time.

Only a weak relation between RFs and the degree of radiological change could be shown in this study. The association with IgG RF and erosive disease is supported by the findings of Hannonen et al. ${ }^{22}$ In contrast with several other authors, ${ }^{11} 2324$ but in agreement with GioudPaquet et $a l^{25}$ and Hannonen et al, ${ }^{22}$ no relation between IgA RF and erosive disease could be found. Winska Wiloch et al, who compared concentrations of IgA RF and IgM RF at the start of a study of early RA with radiographic changes 10 years later, found significant correlations for both isotypes. ${ }^{26}$

The modified joint damage index, omitting the non-erosive severity stage 1 , reflects the irreversible joint abnormalities and thus a later disease stage. The RFs consistently tended to correlate better with this index (table 3 ). There seems to be a time lag for the association between RFs and radiological changes. In the Larsen classification stage 1 is less certain ${ }^{27}$ and an index omitting this stage will therefore be more reliable, which may contribute to the better correlation. On the other hand, an acute 
phase reactant such as CRP correlated best with the ordinary score, indicating that this index better reflects the early inflammatory joint changes.

To obtain a further measure of joint damage progression an index measuring the change in progression rate was constructed. The best regression fit was obtained when variables after one year were analysed. IgG RF contributed most and the correlation was negative, meaning that a high IgG RF reflects a high initial but later decreasing progression rate. This pattern of joint damage progression with an initial high rate followed by a static phase has previously been described in patients with early RA. ${ }^{28}$ It seems that the radiological changes preceded the increase of IgG RF concentration. The change in progression rate index may be useful for testing the temporal connection between the disease process and presumed predictive indicators.

The finding of a delayed IgG RF response together with an earlier observation that RFs tended to correlate better with the modified joint damage index suggests that RFs are not participating directly in the joint damage process but are mainly reflecting a later stage when the damage is already done.

In conclusion, it seems that determination of RF isotypes remains a research tool of limited clinical value in assessing patients with rheumatoid arthritis. This work was supported by grants from the Swedish Rheumatism
Association, the King Gustav V 80th Birthday Fund, the Association, the King Gustav V 80th Birthday Fund, the
Foundation for Aid to the Disabled in Scania, the M Bergwall Foundation for Aid to the Disabled in Scania, the M Bergwall
Trust, Greta and Johan Kocks Trusts, the A Wiberg Trust, the Trust, Greta and Johan Kocks Trusts, the A Wiberg Trust, the
A Osterlund Trust, and the Faculty of Medicine, University of Aund.

1 Eberhardt K B, Svensson B, Truedsson L, Wollheim F A. The occurrence of rheumatoid factor isotypes in early definite rheumatoid arthritis - no relationship with erosions or disease activity. I R Reumatol 1988; 15: 1070-4. 2 Ropes M W, Bennett G A, Cobb S, et al. Diagnostic criteria

3 Ritchie D M, Boyle J A, McInnes J M, et al. Clinical studies with an articular index for the assessment of joint tenderness in patients with rheumatoid arthritis. $Q \mathcal{J}$ Med 1968; 37: $393-406$.

4 Kvien T K, Hoyeraal H M, Sandstad B. Assessment methods of disease activity in juvenile rheumatoid arthritis-evaluated in a prednisolone/placebo double-blind study. f Rheumatol 1982; 9: 696-702.

5 Fries J F, Spitz P, Kraines R G, Holman H R. Measurement of patient outcome in arthritis. Arthritis Rheum 1980; 23: $137-45$.

6 Ekdahl C, Eberhardt K, Andersson S I, Svensson B. Assessing disability in patients with rheumatoid arthritis. Asand $\mathcal{F}$ Rheumatol 1988; 17:263-71.

7 Larsen A, Dale K, Eek M. Radiographic evaluation of rheumatoid arthritis and related conditions by standard reference films. Acta Radiol [Diagn] (Stockh) 1977; 18: 481-91.

8 Truedsson L, Sjöholm A G, Sturfelt G. Complement activating rheumatoid factors in rheumatoid arthritis studied by haemolysis in gel: relation to antibody class and response to treatment with podophyllotoxin derivates. Clin Exp to treatment with podoph

9 Ball J. Serum factor in rheumatoid arthritis agglutinating sensitised sheep red cells. Lancet 1950; ii: $520-4$

10 Anderson S G, Bentzon $M$ W, Houba V, Krag P. International reference preparation of rheumatoid arthritis serum. Bull WHO 1970; 42: 311-8.

11 Teitsson I, Withrington R H, Seifert M H, Valdimarsson $H$. Prospective study of early rheumatoid arthritis. I. Prognostic value of IgA rheumatoid factor. Ann Rheum Dis 1984; 43: 673-8.

12 Young A, Corbett $M$, Winfield J, et al. A prognostic index for erosive changes in the hands, feet, and cervical spines in early rheumatoid arthritis. Br $\mathcal{F}$ Rheumatol 1988; 27: early rhe 101 .

13 Möttönen T T. Prediction of erosiveness and rate of development of new erosions in early rheumatoid arthritis. development of new erosions in early

14 Borg G, Allander E, Lund B, et al. Auranofin improves outcome in early rheumatoid arthritis. Results from a 2 year double blind, placebo controlled study. $\mathcal{f}$ Rheumatol 1988; 15: 1747-54.

15 Scott D L, Dawes P T, Collins M, Stone R. ELISA assays for IgM and IgG rheumatoid factors: their clinical correlations during therapy with slow-acting anti-rheumatic drugs. Clin Rheumatol 1987; 6: 358-68.

16 March R E, Kirwan J R, Reeback J S, Holborow E J. IgM, IgG and IgA rheumatoid factors (antiglobulins) in early rheumatoid arthritis and their production of articular index over one year. Scand f Rheumatol 1987; 16: 407-11.

17 Rudge S R, Pound J D, Bossingham D H, Powell R J. Class specific rheumatoid factors in rheumatoid arthritis: response to chrysotherapy and relationship to disease activity. $\mathcal{J}$ Rheumatol 1985; 12: 432-6.

18 Lessard J, Nunnery E, Cecere F, McDuffy S, Pope R. Relationship between the articular manifestations of rheumatoid arthritis and circulating immune complexes detected by three methods and specific classes of rheumatoid factors. f Rheumatol 1983; 10: 411-7.

19 Robbins D L, Feigal D W, Leek J C. Relationship with serum IgG rheumatoid factor to IgM rheumatoid factor and disease activity in rheumatoid arthritis. $\mathcal{F}$ Rheumatol 1986; 13: $259-62$.

20 Highton J, Hessian PA, Small B, Palmer DG. An assessment of the diagnostic value of quantitative measurements of IgA of the diagnostic value of quantitative measurements

21 Withrington R H, Teitsson I, Valdimarsson H, Seifert M H. Prospective study of early rheumatoid arthritis. II. Association of rheumatoid factor isotypes with fluctuations in disease activity. Ann Rheum Dis 1984; 43: 679-85.

22 Hannonen P, Möttönen T, Teppo A-M, Maury C P J, Oka M . Class specific rheumatoid factors and their complement binding property in the sera of patients suffering from recent-onset rheumatoid arthritis. Clin Exp Rheumatol 1988; 6: 121-8.

23 Tarkowski A, Nilsson L $\AA$. Isotype-specific measurement of rheumatoid factor with reference to clinical features of theumatoid arthritis. F Clin Lab Immunol 1983; 12: 129-35.

24 Arnason J A, Jonsson T H, Brekkan A, Sigurionsson K, Valdimarsson $H$. Relation between bone erosions and rheumatoid factor isotypes. Ann Rheum Dis 1987; 46: ro0-4.

25 Gioud-Paquet $M$, Auvinet $M$, Raffin T, et al. IgM rheumatoid factor (RF), IgA RF, IgE RF, and IgG RF detected by ELISA in rheumatoid arthritis. Ann Rheum Dis 1987;46:65-71.

26 Winska Wiloch H, Thompson K, Young A, Corbett $M$, Shipley M, Hay F. IgG and IgM rheumatoid factors as markers of later erosive changes in rheumatoid arthritis. Scand f Rheumatol 1988; (suppl 75): 238-43.

27 Larsen A, Edgren J, Harju E, Laasonen L, Reitamo T. Interobserver variation in the evaluation of radiologic changes of rheumatoid arthritis. Scand F Rheumatol 1979; 8: $109-12$.

28 Brook A, Corbett M. Radiographic changes in early rheumatoid disease. Ann Rheum Dis 1977; 36: 71-3. 